\title{
Editorial
}

\section{IgG4-Related Disease}

\author{
John H. Stone, ${ }^{1}$ John K. C. Chan, ${ }^{2}$ Vikram Deshpande, ${ }^{3}$ Kazuichi Okazaki, ${ }^{4}$ \\ Hisanori Umehara, ${ }^{5}$ and Yoh Zen ${ }^{6}$ \\ ${ }^{1}$ Rheumatology Unit, Division of Rheumatology, Allergy and Immunology, Massachusetts General Hospital, Yawkey 2, \\ 55 Fruit Street, Boston, MA 02114, USA \\ ${ }^{2}$ Department of Pathology, Queen Elizabeth Hospital, Wylie Road, Kowloon, Hong Kong \\ ${ }^{3}$ Department of Pathology, Massachusetts General Hospital, Warren 2, 55 Fruit Street, Boston, MA 02114, USA \\ ${ }^{4}$ Department of Gastroenterology and Hepatology, Kansai Medical University, Japan \\ ${ }^{5}$ Division of Hematology and Immunology, Department of Internal Medicine, Kanazawa Medical University, 1-1 Daigaku, \\ Uchinada-machi, Kahoku-gun, Ishikawa 920-0293, Japan \\ ${ }^{6}$ Histopathology Section, Institute of Liver Studies, King's College Hospital, Denmark Hill, \\ London SE5 9RS, UK \\ Correspondence should be addressed to John H. Stone; jhstone@partners.org
}

Received 26 December 2012; Accepted 26 December 2012

Copyright (C) 2013 John H. Stone et al. This is an open access article distributed under the Creative Commons Attribution License, which permits unrestricted use, distribution, and reproduction in any medium, provided the original work is properly cited.

Over the past decade and with increasing pace in the last few years, a "new" disease has emerged, gradually affecting a wide range of medical specialties and explaining a host of conditions previously regarded as separate entities. This newly recognized condition is IgG4-related disease (IgG4$\mathrm{RD}$ ), a potentially multiorgan disorder that is characterized by elevated serum $\operatorname{IgG} 4$ concentrations in the majority of cases. IgG4-RD was recognized in modern times in Japan through a series of seminal observations that occurred during the 1990s and the first few years of this century [1-5], but it is clear in reviewing the medical literature that IgG4-RD has been present and reported upon in various guises going back at least to the 1800s [6-11].

In addition to the frequent elevations of serum IgG4 concentrations, certain major pathologic hallmarks are generally present to one degree or another across all organ systems, providing the principal foundation for the belief that the disparate organ manifestations associated with this diagnosis are in fact part of the same systemic disease. These pathologic features include a lymphoplasmacytic infiltrate with a high percentage of plasma cells within the lesion staining for IgG4; a peculiar pattern of fibrosis known as "storiform" fibrosis; a tendency to affect veins in a manner that leads to obliterative phlebitis; and mild to moderate tissue eosinophilia [12].
IgG4-RD appears to sit at an intersection between different inflammatory pathways. Many but not all patients have substantial allergic or atopic histories, and early indications are that a "modified" Th2 response is critical to this condition [13]. Other patients also develop tumefactive lesions leading to misdiagnoses of cancer. Still others have clinical manifestations and serological findings that lead to erroneous classifications of their diagnoses as "connective tissue diseases." The full links between the various inflammatory players in this symphony of inflammation remain to be fully elucidated. It is likely that a broader understanding of the ways in which B and T cells, fibroblasts, plasma cells, immune complexes, and other elements interact in IgG4-RD will provide important insights into the nature of its individual inflammatory constituents and the broader immune system.

IgG4-RD is now recognized as a worldwide disease [14]. The international community convened in Boston in 2011 to compare notes, share experiences, and plan ways for moving ahead in understanding this condition. Building upon crucial earlier work in Japan, consensus papers pertaining to the nomenclature of this condition and to its pathological features have been published $[12,15]$. Japanese investigators have also published diagnostic criteria for IgG4-RD [16].

In this special issue, we are pleased to present more than two dozen papers on IgG4-RD that address a number of facets 
of this condition: from its clinical manifestations to its radiologic features; from its pathology hallmarks to its serologic characteristics; and from its diagnostic challenges to early indications of treatment success. These papers capture the essence of IgG4-RD in 2012 and represent the current stateof-the-art against which future advances will be compared.

John H. Stone

John K. C. Chan

Vikram Deshpande

Kazuichi Okazaki

Hisanori Umehara

Yoh Zen

\section{References}

[1] K. Kawaguchi, M. Koike, K. Tsuruta, A. Okamoto, I. Tabata, and N. Fujita, "Lymphoplasmacytic sclerosing pancreatitis with cholangitis: a variant of primary sclerosing cholangitis extensively involving pancreas," Human Pathology, vol. 22, no. 4, pp. 387-395, 1991

[2] K. Yoshida, F. Toki, T. Takeuchi, S. I. Watanabe, K. Shiratori, and N. Hayashi, "Chronic pancreatitis caused by an autoimmune abnormality. Proposal of the concept of autoimmune pancreatitis," Digestive Diseases and Sciences, vol. 40, no. 7, pp. 1561-1568, 1995.

[3] H. Hamano, S. Kawa, A. Horiuchi et al., "High serum IgG4 concentrations in patients with sclerosing pancreatitis," The New England Journal of Medicine, vol. 344, no. 10, pp. 732-738, 2001.

[4] T. Kamisawa, N. Funata, Y. Hayashi et al., "A new clinicopathological entity of IgG4-related autoimmune disease," Journal of Gastroenterology, vol. 38, no. 10, pp. 982-984, 2003.

[5] M. Yamamoto, H. Takahashi, S. Sugai, and K. Imai, "Clinical and pathological characteristics of Mikulicz's disease (IgG4-related plasmacytic exocrinopathy)," Autoimmunity Reviews, vol. 4, no. 4, pp. 195-200, 2005.

[6] J. Mikulicz, "Über eine eigenartige symmetrische erkränkung der thränen- und mundspeicheldrüsen," in Beiträge zur Chirurgie Festschrift Gewidmet, T. Billroth, Ed., pp. 610-630, Ferdinand Enke, Stuttgart, Germany, 1892.

[7] H. Küttner, "Über entzündliche tumoren der submaxillarspeicheldrüse," Beiträge zur Klinischen Chirurgie, vol. 15, pp. 815-834, 1896.

[8] B. Riedel, "Die chronische zur Bildung eisenharter Tumoren fuhrende Entzündung der Schildrüse," Verhandlung der deutsche Gesellschaft für Chirurgie, vol. 25, p. 101, 1896.

[9] H. Sarles, J. C. Sarles, R. Muratore, and C. Guien, "Chronic inflammatory sclerosis of the pancreas-an autonomous pancreatic disease?" The American Journal of Digestive Diseases, vol. 6, no. 7, pp. 688-698, 1961.

[10] D. E. Comings, K. B. Skubi, J. van Eyes, and A. G. Motulsky, "Familial multifocal fibrosclerosis. Findings suggesting that retroperitoneal fibrosis, mediastinal fibrosis, sclerosing cholangitis, Riedel's thyroiditis, and pseudotumor of the orbit may be different manifestations of a single disease," Annals of Internal Medicine, vol. 66, no. 5, pp. 884-892, 1967.

[11] S. Nakano, I. Takeda, K. Kitamura et al., "Vanishing tumor of the abdomen in patient with Sjogren's syndrome," American Journal of Digestive Diseases, vol. 23, no. 5, pp. 75-79, 1978.
[12] V. Deshpande, Y. Zen, J. K. Chan et al., "Consensus statement on the pathology of IgG4-related disease," Modern Pathology, vol. 25, no. 9, pp. 1181-1192, 2012.

[13] Y. Zen, T. Fujii, K. Harada et al., "Th2 and regulatory immune reactions are increased in immunoglobin G4-related sclerosing pancreatitis and cholangitis," Hepatology, vol. 45, no. 6, pp. 1538-1546, 2007.

[14] J. H. Stone, Y. Zen, and V. Deshpande, "IgG4-related disease," The New England Journal of Medicine, vol. 366, no. 6, pp. 539-551, 2012.

[15] J. H. Stone, A. Khosroshahi, V. Deshpande et al., "Recommendations for the nomenclature of IgG4-related disease and its individual organ system manifestations," Arthritis and Rheumatism, vol. 64, no. 10, pp. 3061-3067, 2012.

[16] H. Umehara, K. Okazaki, Y. Masaki et al., "Comprehensive diagnostic criteria for IgG4-related disease (IgG4-RD)," Modern Rheumatology, vol. 22, no. 1, pp. 21-30, 2012. 


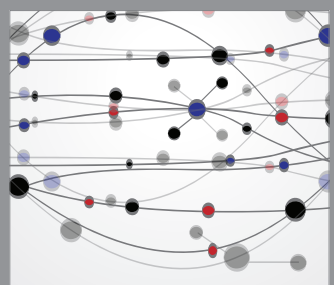

The Scientific World Journal
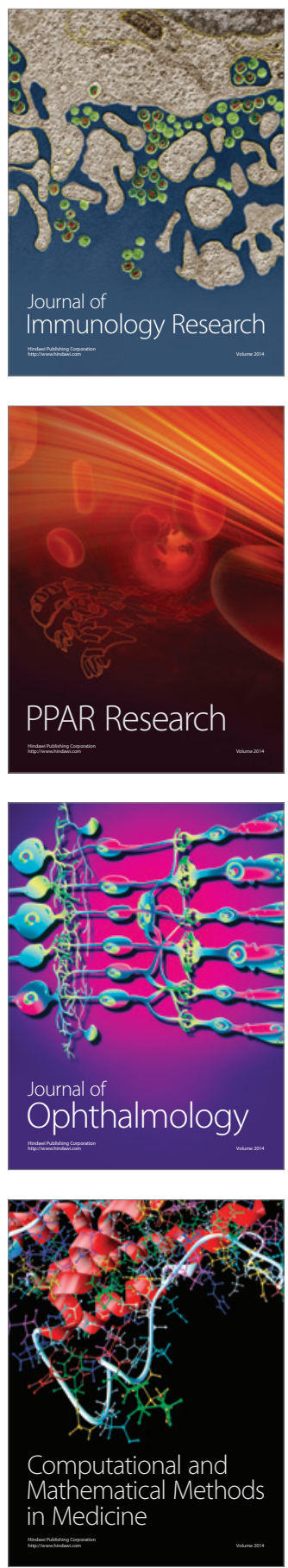

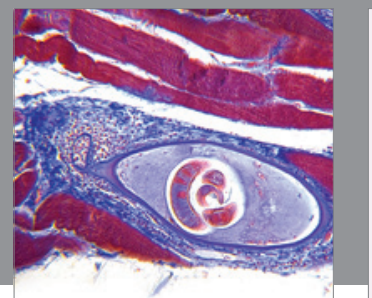

Gastroenterology

Research and Practice
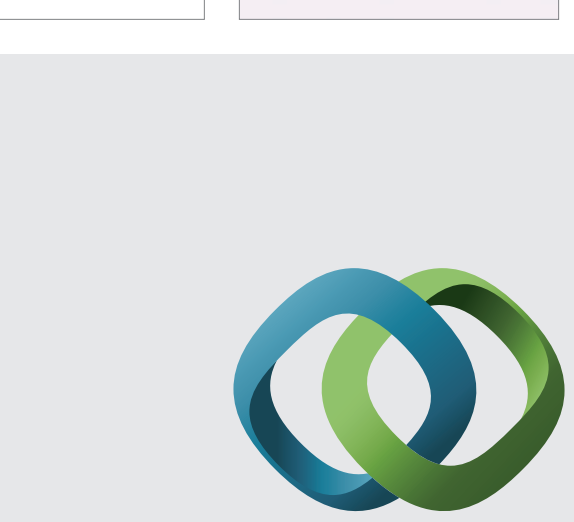

\section{Hindawi}

Submit your manuscripts at

http://www.hindawi.com
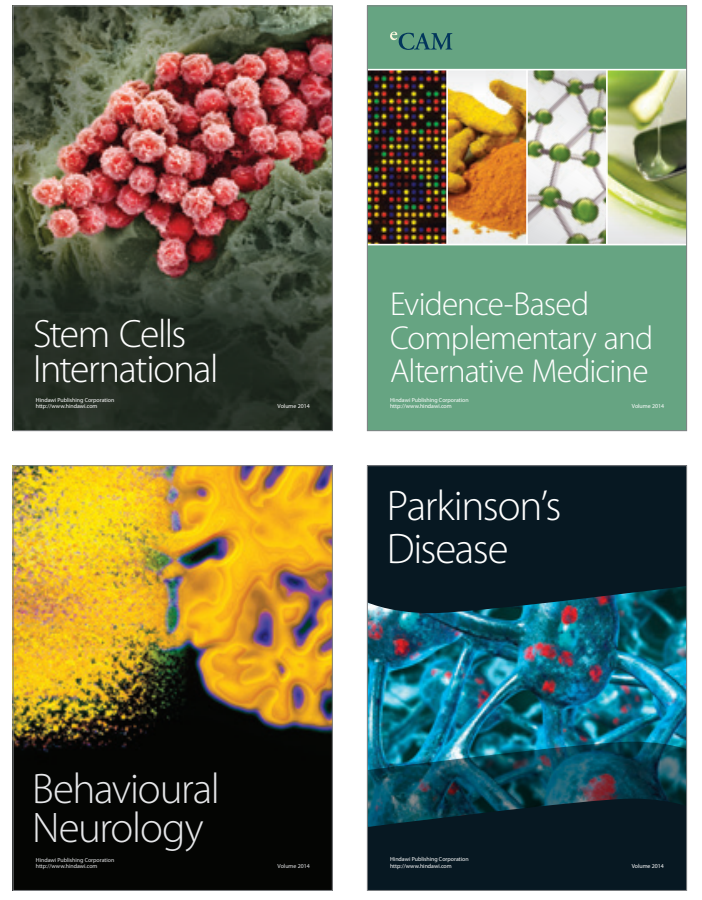
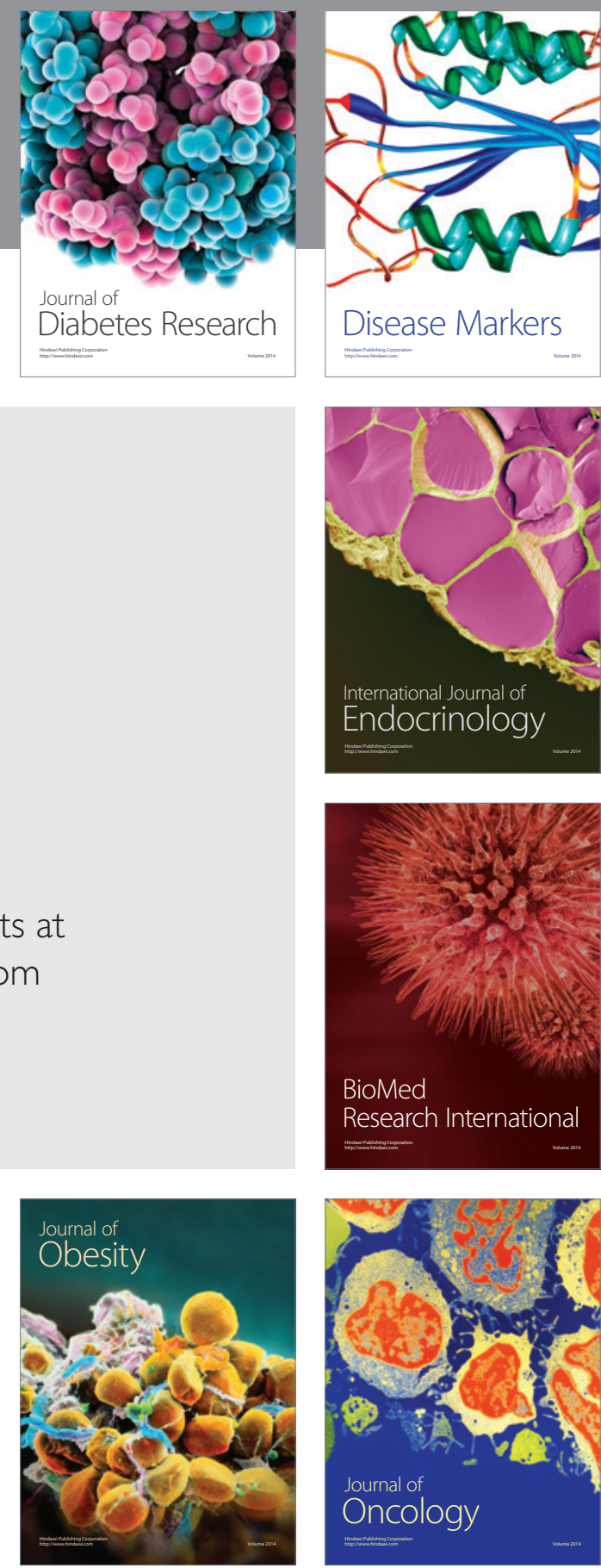

Disease Markers
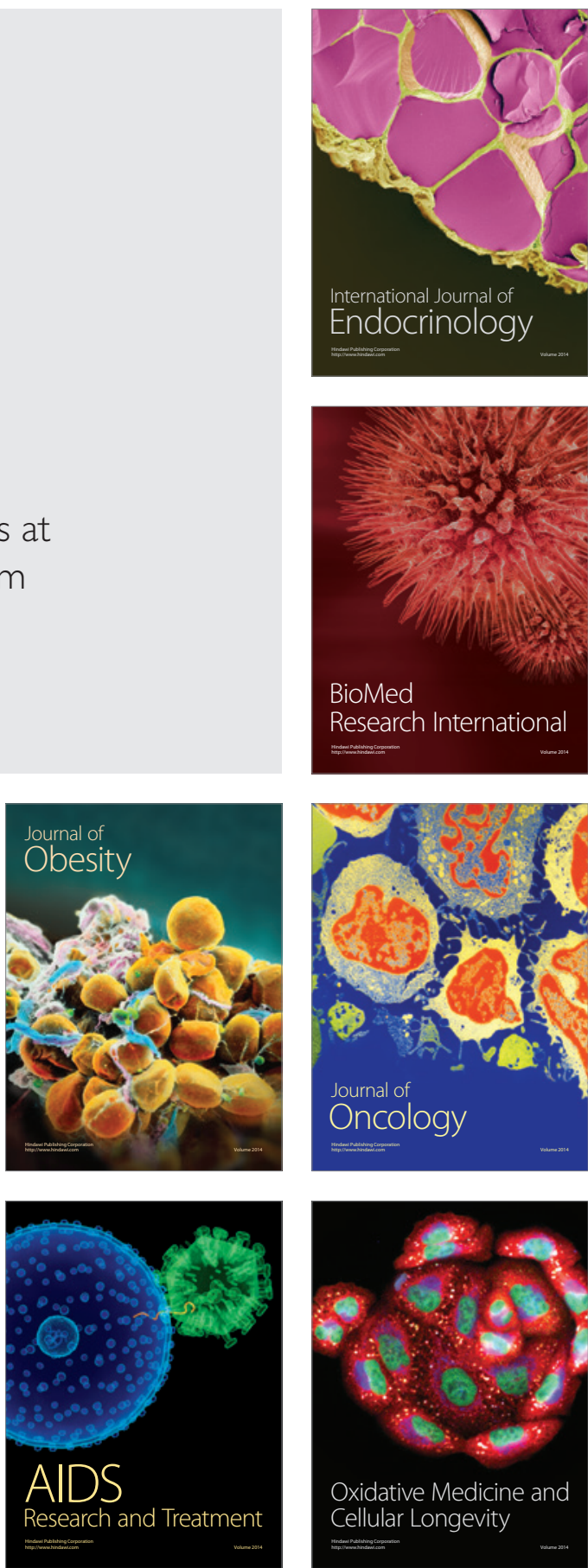